mag. Gozdana

Miglič

Upravna

akademija,

Ministrstvo za

notranje zadeve

\title{
PRIPOROČILA ZA PRIPRAVO PISNIH UČNIH GRADIV
}

\section{Osnovni cilj, namen ter struktura seminarskih gradiv}

S te se kdaj poizkusili učiti iz slabo pripravljenega seminarskega gradiva? Ste imeli pri tem občutek, da neučinkovito izgubljate svoj čas? Ste bili nezadovoljni z avtorjem besedila? Ste bili prepričani, da vaša organizacija brez potrebe zapravlja denar, ko vas pošilja na tako usposabljanje?

Najverjetneje je na gornja vprašanja kar nekaj pritrdilnih odgovorov. Udeleženci in izvajalci različnih oblik usposabljanja in izpopolnjevanja, namenjenih predvsem odraslim, se pogosto srečujemo s problemom pisnih gradiv. Nemalokrat se sploh ne zavedamo, kako pomembno je gradivo, ki ga dobimo na začetku seminarja ali tečaja, saj je navadno to prvi stik med udeležencem in izvajalcem usposabljanja.

Razlogi za takšno stanje so prav gotovo različni, vendar niso nepremostljivi. Organizatorji in izvajalci usposabljanj se kaj lahko izognemo opisanim težavam, če smo pri pripravi pisnih gradiv sistematični in dosledno upoštevamo nekaj osnovnih načel.

Vendar pa je uporaba teh načel povezana $z$ že ugotovljenimi potrebami po usposabljanju in predhodnim izborom učnih metod, sredstev in pripomočkov.

Priprava gradiv in tudi učenje bo hitrejše, lažje in učinkovitejše, če se bomo pri delu zavedali nekaterih osnovnih ciljev in namenov gradiva. Ti so predvsem:
- pomoč pri organizirani predstavitvi informacij,

- lažje sledenje poteku učnega dogodka,

- poudarjanje ključnih točk,

- združevanje pisane besede $\mathrm{z}$ ustrezno ilustracijo,

- vključevanje vizualnih in avditivnih (po potrebi tudi drugih, npr. kinestetičnih) sposobnosti udeležencev,

- možnost kasnejšega ponavljanja in vadbe.

Pri pripravi pisnih učnih gradiv izhajamo iz splošnega načela, po katerem mora biti vsebina gradiva razdeljena na tri temeljna poglavja, in sicer uvod, jedro (razlaga) in zaključek (povzetek).

\begin{tabular}{|c|c|}
\hline POGLAVIE & OUIPOGLAVIA \\
\hline 1. Urod & $\begin{array}{l}\text { Priprovitivadelezence no véenje in ih sezanaiti, o cem se } \\
\text { boco véli. }\end{array}$ \\
\hline 11. Jecro (razlaga) & $\begin{array}{l}\text { Presstaviti nove infornacie, vilugeno s primeri in } \\
\text { praktienim delom, }\end{array}$ \\
\hline 1I. Zakjuček lpovzetele & 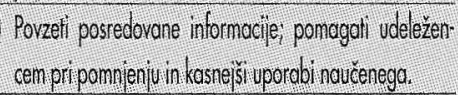 \\
\hline
\end{tabular}

Tabela 1: Splošno načelo - delitev vsebine učnega dogodka na tri temeljna poglavja

\section{NAMENI IN CILJI UVODA}

Upoštevanje načel priprave uvodnega dela učnega dogodka udeležencem olajša učenje, hkrati pa zagotovi tudi izvajalcu boljši pregled nad aktivnostmi, ki jih želi izvesti na začetku usposabljanja. 
Udeleženci bodo sodelovali in se uspešneje učili, če bodo:

- razumeli, kako jim bodo nove informacije koristile pri delu,

- prepoznali korist in smisel dodatnih naporov pri učenju novega,

- videli, da gradivo nudi več, kot sami ta trenutek vedo in znajo.

Udeležencem je učenje olajšano, če:

- vedo, kaj se bodo učili,

- vidijo, kako so informacije, ki se jih bodo učili, organizirane (obseg, podrobnosti, vrstni red ...),

- so informacije razložene na način, ki ga že obvladajo (npr. jezik).

Načela, ki morajo biti vključena v oblikovanje in pisanje uvoda:

- pozornost/motivacija,

- vplivnost/verodostojnost,

- cilji,

- okoliščine/dosedanje poznavanje problematike,

- predstavitev učnega dogodka kot celote.

\section{1. načelo: Pozornost in motivacija}

Udeleženci se učijo le, kadar so pozorni in jih pritegne vsebina učnega dogodka. Če so njihove misli zaposlene s čim drugim in ne $z$ učenjem, ne bo uspeha, in to ne glede na to, kako dobro je pripravljeno gradivo in izvedena vsebina. Motivacija izhaja iz zavesti o koristnosti in vrednosti usposabljanja. Motivacija povečuje in vzdržuje pozornost, brez nje je stopnja pozabljanja večja.

Pozornost in motivacijo spodbudimo, če udeležencem nedvoumno pojasnimo, kakšne koristi bodo imeli od usposabljanja. To dosežemo $\mathrm{z}$ neposrednim povezovanjem usposabljanja $z$ njihovim delom, pri čemer izpostavimo:

- kako se vsebina usposabljanja povezuje s konkretnimi življenjskimi in delovnimi situacijami;

- kakšen je pomen vsebine za: a) udeležence neposredno, b) delo, ki ga opravljajo, c) organizacijo;

- kako bo usposabljanje vplivalo na udeleženčevo delo (lažje, boljše, zanimivejše, pomembnejše ...);

- kako bo učenje vsebine usposabljanja vplivalo na udeležence - njihove neposredne koristi (zadovoljstvo, večje znanje, višja usposobljenost - kvalifikacija, priznanje okolice ...)

\section{2. načelo: Vplivnost in verodostojnost}

Udeleženci verjamejo, poslušajo in se učijo le od ljudi in iz gradiv, za katere menijo, da so »vplivni« in »verodostojni« oziroma imajo potrebno strokovno avtoriteto. Gradiva so "vplivna in verodostojna «, če so:

- strokovna (vsebina),

- privlačna in pregledna (izgled).

Udeleženci se ne učijo iz gradiv, če so prepričani, da vedo več, kot jim nudi določeno gradivo. Prepričani morajo

Gradivo mora imeti potrebno strokovno avtoriteto. biti, da gradivo zajema vsebine, ki se jih učijo, na dokončen in suveren način.

Strokovnost dosežemo, če:

- uporabljamo najnovejše dosegljive podatke in informacije,

- če podatki in informacije izvirajo iz virov, ki jih udeleženci ocenjujejo za verodostojne (raziskave, področne strokovne ekspertize, strokovna praksa ...),

- vključujemo podatke in informacije, ki jih udeleženci že poznajo.

Načini zagotavljanja verodostojnosti usposabljanja; 
- predstavitev strokovnosti avtorja učnega gradiva/izvajalca usposabljanja;

- uporaba in navajanje ustreznih virov in literature (raziskave, knjige, zakoni, dokumenti ...) in že uveljavljene strokovne prakse, na kateri mora tudi sicer pretežno temeljiti usposabljanje;

- nakazovanje povezav s sodobnimi idejami, pobudami, rešitvami ..., ki se nanašajo na obravnavano tematiko;

- upoštevanje odnosa in stališč udeležencev do obravnavane teme ter znanja in informacij, ki jih že imajo.

Privlačnost gradiva pomeni oblikovati gradivo tako, da bo privlačno na pogled in bo spodbujalo udeležence $\mathrm{k}$ študiju. Pri tem je treba upoštevati način vezave/spenjanja (estetski vidik, funkcionalnost), razdelitev v poglavja, čitljivost, številčenje, pisavo in velikost črk, skice, diagrame, slike, prostor za beležke, stil pisanja, jezik, slovnico itd.

\section{3. načelo: Ciljii}

Udeleženci se učijo bolje, če že na začetku natančno vedo, kaj se bodo učili in kaj bodo

Poznavanje ciljev omogoča boljšo selekcijo informacij. po končanem usposabljanju sposobni storiti (znati, vedeti, razumeti ...) bolje. Poznavanje ciljev jim olajša osredotočanje na bistvene informacije in pomaga pri izločanju nepomembnih ali motečih informacij. Postavitev ciljev jim omogoči tudi merjenje njihovega napredka.

Cilji morajo biti predstavljeni že uvodoma in so najučinkovitejši, če so:

- specifični,

- konkretni,

- merljivi,

- vedenjski,

- povezani z dejansko situacijo.

\section{4. načelo: Okoliščine in dosedanje poznavanje problematike}

Učenje je boljše in lažje, če so informacije, ki jih morajo udeleženci obvladati, postavljene $\mathrm{v}$ znane okoliščine, pri tem pa so uporabljeni že znani koncepti in izrazoslovje. Učenje novega poteka s pomočjo "pripenjanja " in s povezovanjem novih informacij $\mathrm{z}$ že obstoječimi ter $\mathrm{s}$ primerjanjem in ugotavljanjem enakosti oziroma podobnosti. Ko udeleženci dobijo novo informacijo, iščejo v svojem znanju že podobno obstoječo informacijo, na katero »obesijo" novo informacijo.

Če so torej nove informacije razložene tako, da uporabljajo spominske »kljuke«, je učenje lažje. V nasprotnem primeru, kadar nove informacije niso razložene $\mathrm{v}$ besednjaku ali na način, ki ga že poznajo, je učenje težje, časovno daljše in navadno manj uspešno.

Vključevanje znanih okoliščin in že obstoječega poznavanja problematike pomeni:

- povezovanje novih informacij s tistimi, ki jih udeleženci že imajo;

- spodbujanje k iskanju »kljuk « v obstoječem znanju, na katere udeleženci pripenjajo nove informacije.

Načini za vključevanje že znanega:

- uporaba analogij/podobnosti,

- povezovanje z znanimi (domačimi) situacijami,

- izhajanje iz konkretnega (primeri) k splošnemu (načela),

- dodajanje podrobnosti že znanim informacijam,

- spodbujanje k spominjanju in nadgrajevanju,

- uporaba znanega besednjaka, konceptov itd. 


\section{5. načelo: Predstavitev učnega dogodka kot celote}

Odrasli se učijo bolje, če imajo predstavo (sliko) celote prej, preden se posvetijo podrobnostim. Tako imenovani mentalni set je postavljen, če so udeleženci seznanjeni s celotno strukturo že na začetku usposabljanja oziroma če vidijo gozd prej, kot se začno ukvarjati z drevesi.

To dosežemo s kratko in jedrnato, vendar še vedno dovolj natančno predstavitvijo vseh informacij, ki se jih morajo naučiti. Ustvarjanje celote omogoča udeležencem osredotočanje na informacije, ki se jih bodo učili, in zavira morebitne neustrezne odmike od učenega. Tak pristop zagotovi strukturo (podobno obrobi mozaika), ki jo udeleženci v nadaljevanju usposabljanja polnijo $\mathrm{z}$ delci prihajajočih informacij. Struktura hkrati ponazarja organizacijo učnega dogodka ter omogoča ugotavljanje trenutne stopnje napredka.

Načina za doseganje zavedanja/predstave celote sta:

- kratka in jedrnata predstavitev informacij, ki se jih je treba naučiti;

Primeri:

a) Udeležencem povejte: $~ V$ tem poglavju se boste naučili ... «;

b) Napišite odstavek, ki naj v ne več kot 7 stavkih povzame glavne koncepte, načela, postopke, ki se jih je treba naučiti - po enega v vsakem stavku.

- predstavitev organiziranosti učnega dogodka s pomočjo zaporedja vsebin in poglavij ter njihovega obsega;

Možni načini:

a) zaporedno številčenje vsebin (1.

2. - ; 3. -);

b) preglednice s številkami v levem in temami v desnem stolpcu;

c) »flowchart «, ki kaže potek in zaporedje tem; č) »mapiranje « učnega dogodka (pri tem je vsaka tema navedena $\mathrm{v}$ svojem kvadratku, koraki in njihovo zaporedje so ponazorjeni s puščicami med kvadratki).

Nekaj načinov razlag posameznih poglavij učnega dogodka in oblika, $v$ kateri naj bodo zapisane:

- poglavja, našteta poimensko,

- kratek opis vsakega poglavja,

- razložena oblika, v kateri je napisano posamezno poglavje, glede na različne tipe informacij (poudarjen tisk, vrste in velikosti pisav, vrstične oznake, robovi, zamiki itd.), - pri vsakem poglavju vpisana aktivnost, ki jo bodo izvajali udeleženci (npr. vprašanja odgovori).

\section{NAMENI IN CILJI JEDRA}

Medtem ko je uvod namenjen razlagi, "zakaj se učiti «, osrednji del vsebuje konkretne informacije in vsebine, ki se jih morajo udeleženci naučiti.

Načela, ki morajo biti upoštevana pri oblikovanju in pisanju jedra:

- delitev na manǰ̧se dele,

- ilustracije,

- ustrezni primeri,

- oblikovanje gradiva,

- vaje in utrjevanje,

- povratna informacija.

\section{6. načelo: Delitev na manjše dele}

Udeleženci si lahko zapomnijo naenkrat le omejeno količino informacij. V povprečju je ta sposobnost omejena na 7 smiselnih elementov informacije (plus ali minus 2). Če predstavljena količina presega to omejitev, se lahko pojavijo težave pri sprejemanju in obdelavi informacij. 


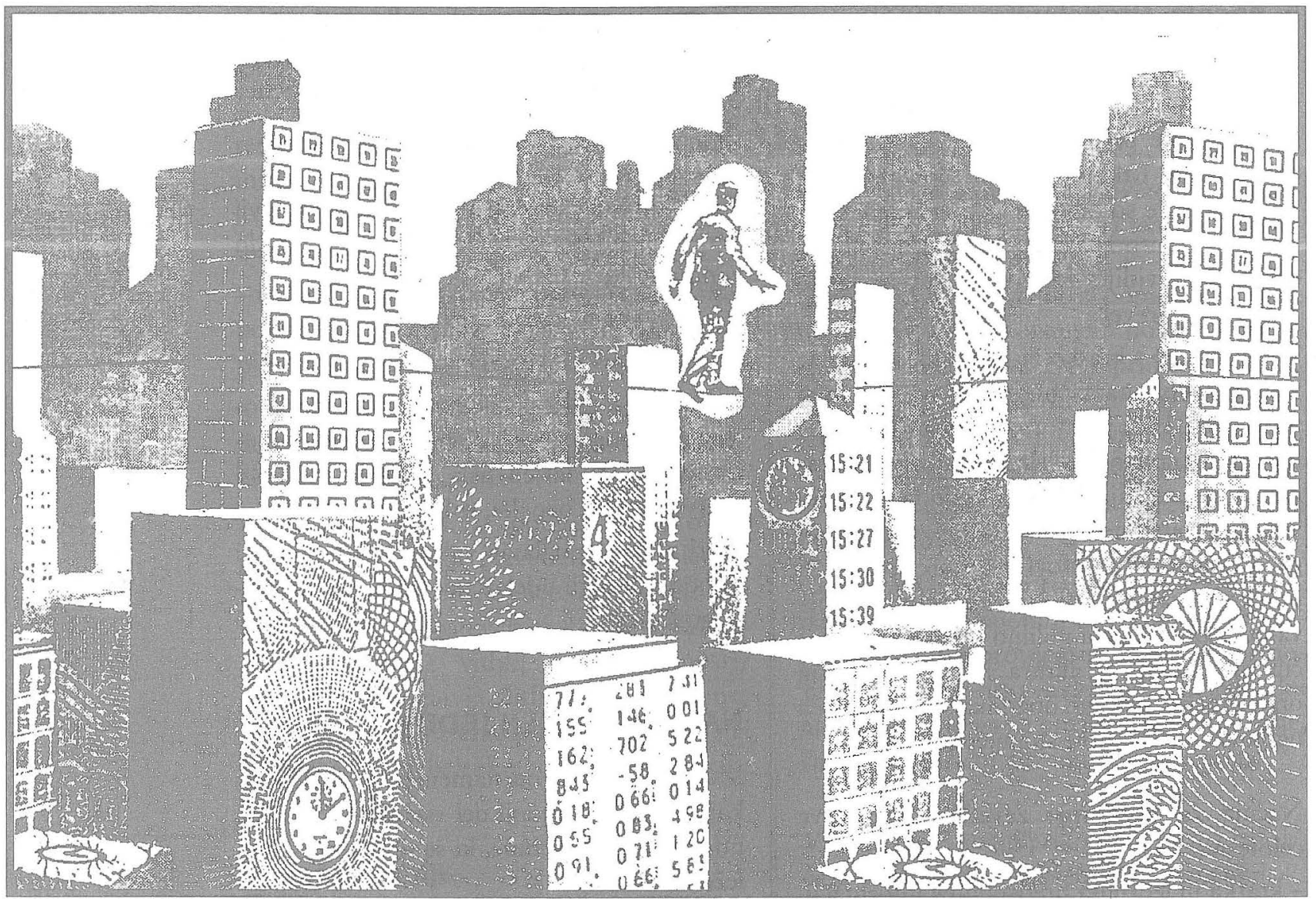

Udeleženci si laže zapomnijo večjo količino informacij, če so le-te urejene v posamezne sklope/skupine. Posamezni sklopi morajo imeti samostojen naslov in ne smejo vsebovati več kot 7 elementov. $\mathrm{V}$ tem primeru si udeleženci zapomnijo naslove vseh sklopov in večino elementov v posameznih sklopih.

Tako mora biti npr. seznam 15 korakov razdeljen v 3 sklope, od katerih vsak vključuje po 5 korakov. Pri tem si udeleženci zapomnijo naslove vseh 3 sklopov kot samostojen sklop ( $v$ tem primeru prvega od štirih), ki ga prav tako sestavljajo 3 elementi.

Postopek razstavljanja in "grupiranja « informacij (kompleksna dejstva, pravila, postopki itd.) v manjše in laže obvladljive sklope vključuje naslednje korake:

$1 / 90$

- ugotoviti, ali obstaja več kot 7 točk, idej,

korakov, konceptov itd. v učnem dogodku; če je odgovor pritrdilen, potem je treba informacijo:

- razdeliti v 7 ali manj logičnih sklopov,

- poimenovati vsak sklop,

- našteti naslove teh sklopov v samostojnem sklopu na začetku,

- v nadaljevanju v pravilnem zaporedju razstaviti vsak sklop posebej na točke, korake itd.

Primer: Pričujoči prispevek o pripravi pisnih gradiv vsebuje 13 načel. Gradivo je razdeljeno na tri dele: uvod, jedro - razlaga in zaključek - povzetek. (1. sklop). V uvodu je združenih prvih pet načel (2. sklop), naslednjih 6 načel je predstavljenih $\mathrm{v}$ jedru (3. sklop), medtem ko sta zadnji načeli zajeti $\mathrm{v}$ zaključku (4. sklop). 


\section{7. načelo: Ilustracije}

Udeleženci se iz gradiva učijo bolje, če le-to vsebuje besedilo in ilustracije. Besedno sporočilo ima pogosto večji učinek, če je podprto $\mathrm{z}$ ustrezno ilustracijo, in obratno. Glavni nameni in prednosti uporabe ilustracij so vplivanje, usmerjanje, nadzor, organiziranje in poenostavljanje sprejemanja in razumevanja sporočil.

Slikovna podpora in vizualizacija je nujna, kadar predstavljamo:

- pojme, koncepte, postopke,

- korake v postopku,

- specifične podrobnosti,

- posplošene oblike,

- relativno velikost in obseg,

- relativne razdalje itd.

Osnovni pristopi k učinkovitemu združevanju besedila in ilustracij:

- privlačne ilustracije;

- uporaba kratkih naslovov, podnaslovov, vprašanj ali razlag, ki pomagajo udeležencem uvrstiti in klasificirati ilustracijo, jih usmerjajo pri opazovanju ter jim pomagajo pri pomnjenju ilustracije;

- v začetku uporaba manj podrobne ilustracije, ki olajšuje pregled nad celoto koncepta ali predmeta;

- v nadaljevanju uporaba bolj podrobne ilustracije, ki ilustrira specifične primere ali detajle večje celote;

- pri poudarjanju podrobnosti je skica primernejša kot slika (npr. predmeta);

- pri ponazarjanju gibanja, hierarhičnih odnosov, poudarjanju in ločevanju posameznih elementov itd. je učinkovita uporaba črt različnih kakovosti (debelina, pike, črte ...), puščic, barv;

- pri celovitejših in obsežnejših ilustracijah naj bo prikaz podrobnosti razbit na sklope s po 7 elementi, pri čemer mora biti vsak sklop zaključen in samostojen del znotraj celote.

\section{8. načelo: Ustrezni primeri}

Pojme laže razumemo (ali pa sploh samo) in si bolje zapomnimo, če so le-ti predstavljeni s pomočjo primerov.

Primeri torej:

- ponazarjajo pojme ali koncepte ter jih povezujejo s konkretno situacijo, predmetom, opisom ...;

- vsebujejo vse pomembne značilnosti, ki odlikujejo neko idejo ali koncept in jih ločijo od drugih;

- lahko vsebujejo različno število elementov, ki niso značilni za predstavljen pojem ali koncept;
Raba pravilnih in namerno napačnih primerov povezuje pojme s konkretno situacijo.
- se razlikujejo v zahtevnosti njihove prepoznavnosti in razumljivosti od enostavnih do zelo zahtevnih.

Opisi in primeri navadno niso dovolj. Pogosto je za ponazoritev posameznega pojma dopuščena tudi zavestna uporaba napačnih primerov, ki kot kontrast omogočajo:

- prepoznavanje omejitve pojma ali koncepta,

- razlikovanje na prvi pogled podobnih pojmov ali konceptov,

- posploševanje in prenos (tudi izkrivljen) »idealnega « opisa pojma ali koncepta iz učnega okolja v različne življenjske in delovne situacije.

Pri uporabi primerov moramo biti pozorni, da:

- primeri ustrezajo ciljni skupini udeležencev; 
- uporabljamo kar največ primerov (vsaj dva ustrezna in dva neustrezna), s čimer ponazorimo razpon ideje, koncepta, načela, postopka itd.;

- začenjamo z najenostavnejšimi primeri ter nato stopnjujemo njihovo zahtevnost.

\section{9. načelo: Oblikovanje gradiva}

Besedilo je laže obvladljivo, če je ustrezno in pregledno oblikovano. Ustrezna podoba besedila zato olajšuje učni proces, ga spodbuja in veča njegovo kakovost, ker:

- lajša branje besedila,

- nedvoumno povezuje besedilo z ilustracijami,

- kaže jasen organizacijski vzorec vsebine,

- poudarja pomembno,

- usmerja pozornost h ključnim točkam,

- ločuje različne bloke informacij,

- omogoča hitro iskanje, pregled in ponavljanje informacij,

- zagotavlja dovolj praznega prostora za zapiske.

Pravilno oblikovano gradivo vključuje:

Ustrezna grafična podoba seminarskega gradiva spodbuja učni proces.

- ustrezno razmerje med praznim prostorom in besedilom na posameznih straneh;

- uporabo besed ali fraz, ki poimenujejo poglavja, podpoglavja ali sklope besedila;

- poudarjanje ključnih besed z različnimi pisavami, okrepljenim ali poševnim tiskom, podčrtavanjem, barvami, kvadratki itd.;

- uporabo tabel, grafov, matric, diagramov, skic itd.;

- primerno razmerje med praznim prostorom, besedilom in grafiko, ki morajo učinkovati kot celota.
Praktična navodila za oblikovanje gradiva:

- dovolj praznega prostora na vsaki strani (razbije gostoto in zmanjša vtis natrpanosti);

- ključne besede ali kratke fraze, značilne za posamezne teme, umestimo na levo stran lista, njihovo razlago pa na desno stran;

- besedilo ali dele besedila, ki so izredno pomembni, vpišemo v kvadrate;

- uporaba podčrtanega, krepkega ali poševnega tiska za ključne dele besedila;

- ilustracij in pripadajočega besedila z razlago ne smemo ločevati;

- pri naštevanju je primernejša uporaba vrstičnih oznak (npr. $\bullet,>, *$ ) kot številk;

- številčenje uporabljamo le pri naštevanju zaporednih korakov (npr. kakega postopka), ki morajo biti izvedeni v določenem vrstnem redu;

- obsežnejša naštevanja naj bodo razdružena na krajša ter poimenovana $\mathrm{z}$ ustreznimi vmesnimi naslovi;

- stavki naj bodo kratki in združeni v prav tako kratke odstavke;

- za beležke naj bo dovolj praznega prostora;

- naslovi poglavij, podpoglavij, tem in drugih manjših vsebinskih enot se morajo med seboj razlikovati (pisava, tisk) glede na njihovo "težo « in pomen, vendar pa morajo biti enotni v celem gradivu;

- ilustracije morajo biti vključene v besedilo na smiselnih mestih ali pa izjemoma na kon$\mathrm{cu}$ besedila ( $\mathrm{v}$ tem primeru mora biti to $\mathrm{v}$ besedilu jasno označeno);

- na začetku gradiva mora biti kazalo vsebine, vključno z morebitnimi prilogami.

\section{0. načelo: Vaje in utrjevanje}

$\mathrm{Za}$ učinkovito učenje ni dovolj le teoretična razlaga. Udeleženci morajo imeti možnost konkretne uporabe novih informacij, npr. 
preizkušanje novih veščin. Zato mora gradivo vsebovati ustrezna vprašanja in vaje za ponavljanje in utrjevanje. Pri tem morajo biti vaje $\mathrm{v}$ obliki, $\mathrm{v}$ kateri bodo udeleženci nova znanja in veščine uporabljali v svojem delovnem okolju. Našteti na pamet korake kakega postopka najverjetneje ni veščina, ki bi jo delavec potreboval na delovnem mestu. $\mathrm{Na}$ drugi strani pa bo dejansko izvajanje postopka, čeprav tudi samo v simulirani situaciji, imelo zaželene učinke.

Vaje morajo biti razporejene skozi vse gradivo. Ena sama vaja ni dovolj. Udeleženci morajo imeti priložnost vaditi vsako novo pridobljeno veščino ali znanje sproti (npr. vsak korak kakega postopka ločeno in na koncu tudi kot celoto). Če so postopki zahtevni ali dolgi, mora biti zagotovljeno ponavljanje posameznih korakov (npr.: Ko so udeleženci obvladali 3 . korak šest korakov dolgega postopka, morajo imeti možnost, da vadijo ne le 3 . korak, ampak znova tudi prva dva itd.).

Načela vključevanja vaj v gradivo:

- zagotovljeno mora biti kar največje število vaj ali vprašanj, ki omogočajo učenje in utrjevanje novega znanja in veščin;

- vaje morajo biti razporejene skozi cel učni dogodek in ne smejo biti zbrane le na enem mestu;

- vaje morajo biti vključene najmanj na koncu vsakega poglavja ali sklopa;

- vaje morajo biti oblikovane tako, da ustrezajo namenom in ciljem usposabljanja in se ujemajo s situacijo v delovnem okolju in potrebami delovnega mesta;

- vaje morajo spodbujati razmišljanje in obdelavo informacij in ne le njihovo pomnjenje;

- vaje morajo spodbujati udeležence $k$ samostojni vadbi tudi po končanem usposabljanju.

\section{1. načelo: Povratne informacije}

Med vadbo in po njenem zaključku morajo udeleženci dobiti informacijo o svoji uspešnosti. Če so bili njihovi odgovori/akcije/reakcije pravilni, potrebujejo informacijo, ki jim to potrdi. Prav tako potrebujejo informacijo, kadar so bili neuspešni. $V$ tem primeru jim informacija pove:

- da so bili odgovori nepravilni,

- zakaj so bili nepravilni,

- kateri so pravilni odgovori in zakaj so pravilni.

Zagotavljanje povratnih informacij:

- omogoča udeležencem spremljati kakovost njihovega učenja,

- odpravlja napake v učenju,

Gradivo mora vsebovati tudi povratno informacijo o kakovosti učenja udeležencev.
- motivira za nadaljnje učenje.

Povratne informacije morajo biti posredovane neposredno po končani vaji, tako časovno kot prostorsko (v gradivu). Po možnosti naj bodo torej odgovori na isti strani kot vprašanja, seveda pa naj oblika gradiva zagotovi, da udeleženci ne bodo videli odgovorov pred reševanjem.

Povratna informacija mora vključevati:

- razlago, kako uporabiti povratno informacijo pri ugotavljanju ne/pravilnosti odgovorov;

- pravilen odgovor;

- razlago, zakaj je odgovor pravilen (ta razlaga je izražena $z$ drugimi besedami in na drugačen način, kot je bilo v gradivu razloženo prvič);

- »pohvalo« ali spodbudo za nadaljnjo motivacijo;

- če je le mogoče, nekaj primerov najpogostejših napačnih odgovorov in razlag, zakaj so nepravilni; 


\begin{tabular}{|c|c|c|c|}
\hline NACEOO & $\begin{array}{l}\text { KUUČNA VPRAŚSANA, POVEZANA SPRIPRAVO } \\
\text { UČNEGA GRADVIA }\end{array}$ & 8. USTREZN PRIMERI & 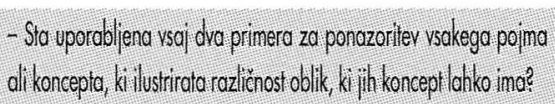 \\
\hline W100 & & & - Vsebujejo primeri najpomemonejeje znocilhosti idaje, ki o loćujejo \\
\hline 1.POZORNOSTI & - le vsebina usposabblianja pomembra za udeleżence, & & oddrugihidej? \\
\hline MOTVACHA & nilhovo dele in organizacijo? & & 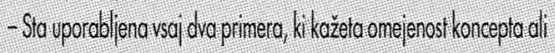 \\
\hline & 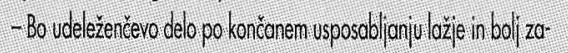 & & poima? \\
\hline & nimivo? & & - So primer ustrezni glede na cilino skupino vedeležencev? \\
\hline & - Bo udeleženec boli vecinkovit, upoštevan in nagrejen? & & - Se primeri sopnivieje glede na nïhovo razunliviost in zahtennosi? \\
\hline 2.VPLINOST/ & - So novedene avtojieve reference? & 9 . OBIKOVANE GRADIVA & - Je na posamezni strani dovol praznega prostora? \\
\hline VERODOSTONOST & - So cilirane uporabliene raziskove in strokovno praksa? & & - So za ponazoritev processov in potekov uporabilifene matrice, labe. \\
\hline & - Obstajajo povezave z novimi idejami in idejami, kiso jhudelezen. & & le, skice id?? \\
\hline & cispoznali žepred usposablianiem? & & 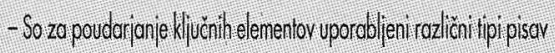 \\
\hline & - Daie gradivo ze na privi pogled vis strokovnosti in kakovosti? & & intiska? \\
\hline 3. CUI & -Socilifi asno postavileni? & & - So zarod bolišega pregleda in hitrejěega iskanja kijučne besede \\
\hline & - Se c ili nanašsjo na pridobivivanje veš̌̌in? & & dilfraze uporabljene kot oponbe v vstreznem delu besedila |npr. rob \\
\hline & - Se clifinancśäip na spremembe vecenja? & & dipodnaslovit? \\
\hline 4. OKOLSECNE/DOSEDANE & - Je nova informocija povezana z że obstojecéim znanjem & & - Je upostevana razilika med oznocévonjem in številcenjem? \\
\hline POZNAVANEE & udeležncer? & 10. VAJEINUIREVVANE & - So na konou vsokega poglevja vaje al i vprośanja? \\
\hline PROBLEMATIKE & - Je bilo udeležencem svetovano, ketere że obstojece povezave naj & & - Se vaje viemajos sclij usposab janja in zahtevami delornega okolia? \\
\hline & uporabijo? & & - Sto vsoi dve vai namenieni pricobbivanju véšcin? \\
\hline & - Je bilo staro znanje osvezéno? & & - So vaje ustrezno razporejene skozi gradivo in niso le na enem mestu? \\
\hline & - Upordilia nova rozzlaga za povezzovarje ze znane kancepte in be & 11. POVAINA & - Je povratha informacija sprotha? \\
\hline & sedajok? & NFORMACIA & - So pravilhi odgovori razlozeni? \\
\hline 5. PREDSTAVTEV UCNEEGA & - Je novo informocija predstovijena krakko inj jeernato? & & - Vkjučujejo vaje tudi spodbudo zo nodalinie delo? \\
\hline DOGODKA KOT CELOTE & - le razložena organizironost; zaporeceje, obseg in oblika uénego & & - So vključeni inajpogostej̈: neprovihi odgovori z rozlogo? \\
\hline & dogodka? & & - Je udelezéncem onemogocéno vnoprej videli provilhe odgovore in \\
\hline JEDRO & & & resíve? \\
\hline 6. DELITEY NA MANISE DELE & 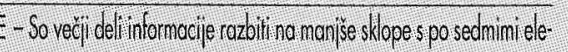 & ZAKLLCEK & \\
\hline & mentí & 12. POVZETEK & - So vse bistvene informacije viluciene in povezzone? \\
\hline & -So posamezni sklopi poimenovani? & & - So intomacile podane na drugacéen način? \\
\hline & - le pri iskop sestavijen iz nastovor noslednith sklopor, ki mu sedijo & & -So.kliučne tocke izpostavijene? \\
\hline & vistem zaporedju? & & - Je vključen primer, ki razzisija oplikacijo intormacije? \\
\hline 7. LUSRRACIE & - So lustracie opremliene z nos lovom di irozlogo? & 13. POMNENEE & - So uporabljene klučcne besede, gesta, analogie, simboli? \\
\hline & - So ilustrocie razporejene od mani zahtevnih k boli podrobnim in & NGRAQNO & - Je proksa povezanas testom (preizusuam znanje in razumevanjal, \\
\hline & - So lustracie poctrobnosti risbe dlisilike? & & - So gradivu dodani razlièni pripomooḱ, kot npr. opomaiki, obrazci, \\
\hline & 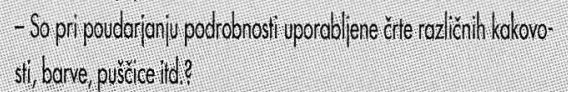 & & 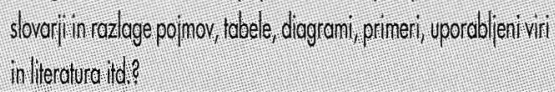 \\
\hline
\end{tabular}

Tabela: Opomnik za pripravo pisnih gradiv

- priporočila udeležencem, katerih odgovori so bili nepravilni, za nadaljnje delo;

- poglavja s povratnimi informacijami morajo biti enostavna, jasna in konkretna.

\section{NAMENI IN CILJI ZAKLJUČKA}

Nameni in cilji zaključka. Udeleženci laže uporabijo novo znanje in veščine, če si zapomnijo, kaj so se učili, če vedo, kdaj upora- 
bljati novo znanje/veščine, in če imajo ustrezno gradivo (npr. priročnike).

Za učinkovito povzemanje sta pomembni dve načeli:

- povzetek.

- pomnjenje in gradivo.

\section{2. načelo: Povzetek}

Povzetek je zlasti pomemben pri večjem obsegu novih informacij. Pri tem ponavljanje informacij $\mathrm{z}$ istimi besedami ni dovolj. $\mathrm{Za}$ boljše razumevanje, učenje in pomnjenje morajo biti nove informacije povedane na drugačen način. Biti morajo povezane, pri čemer morajo biti izpostavljene ključne točke. Za pomoč pri posplošenju in ustvarjanju celotne slike mora biti povzetek podkrepljen $\mathrm{s}$ »finalnim « primerom, ki povezuje in ponazarja vse dele nove informacije.

Povzetek, prav tako tudi povzetki vsakega poglavja posebej, mora torej vsebovati:

- vse bistvene informacije, povezane med seboj,

- razlago informacije na drugačen način,

- ključne točke,

- primer, ki povezuje informacijo s situacijo, ki v prvotni razlagi še ni bila zajeta.

Tudi v povzetku je priporočljivo uporabljati orise, tabele, sheme, diagrame ali opomnike ter ključne besede in vprašanja.

\section{3. načelo: Pomnjenje in gradivo}

Nikakor ne moremo pričakovati, da se bo udeležencem uspelo zapomniti vse informacije že med samim potekom učnega dogodka. Za uspešno pomnjenje in kasnejše spominjanje so odločilni trije elementi:

- oporne spominske točke (ključne besede, analogije, simboli, slike, podobne situacije ali zgodbe), ki pomagajo priklicati v spomin informacijo kot celoto in tudi njene podrobnosti;

- zaključna vaja (lahko tudi test), ki zahteva spominjanje ali uporabo vsega novega;

- gradiva in priročniki (opomniki, tabele, obrazci, vzorčni dokumenti).

Našteta načela niso le opora pri pisavi učnih gradiv, pač pa so lahko tudi dobrodošla pomoč pri ocenjevanju kakovosti že napisanih gradiv. Tabela št. 2, opomnik za pripravo učbenikov ali priročnikov, na kratko povzema vse nujne sestavne dele gradiva ter vprašanja, na katera mora biti odgovor vedno »da «. V nasprotnem primeru moramo gradivo znova preučiti in odpraviti njegove pomanjkljivosti.

\section{LITERATURA}

Corder, Colin (1990): Teaching Hard, Teaching Soft. A Structured Approach to Planning and Running Effective Training Course. Aldershot: Gower.

Silber, H. Kenneth, Stelnicki, B. Michael (1987): Writing Training Materials. V: Robert L. Craig (ur.), Training and Development Handbook, A Guide to Human Resource Development, McGraw-Hill Book Company, 263-285.

Silberman, Mel (1990): Active Training. A Handbook of Techniques, Designes, Case Examples, and Tips. Lexington Books. 